\title{
Carbonitride Dissolution and Austenite Grain Growth in a High Cr Ferritic Heat-resistant Steel
}

\author{
Xingang TAO, Jianfeng $\mathrm{GU}^{*}$ and Lizhan HAN
}

Shanghai Key Laboratory of Materials Laser Processing and Modification, School of Materials Science and Engineering, Shanghai Jiao Tong University, Shanghai, 200240 P.R. China.

(Received on February 13, 2014; accepted on April 11, 2014)

\begin{abstract}
Dissolution of carbonitrides and growth of austenite grain in X12CrMoWVNbN10-1-1 steel under various austenitizing conditions were investigated. The experimental results showed that the carbonitrides existing in after-forging heat treated state were mainly $\mathrm{Cr}_{23} \mathrm{C}_{6}$ and small amounts of $\mathrm{NbN}$ and $\mathrm{Cr}_{2} \mathrm{~N}$. However, $\mathrm{Cr}_{23} \mathrm{C}_{6}$ and $\mathrm{Cr}_{2} \mathrm{~N}$ precipitates were dissolved completely after austenitization at $1070^{\circ} \mathrm{C}$ for 60 min or at $1200^{\circ} \mathrm{C}$ for $15 \mathrm{~min}$, only the $\mathrm{NbN}$ particles left. The state of dissolution of NbN particles was also studied in detail as a function of austenitization holding time $\left(t_{A}\right)$ at different temperatures. Initially, the $\mathrm{NbN}$ particles dissolved with increasing $t_{A}$ at $1070^{\circ} \mathrm{C}$. When $t_{A}$ reached over $360 \mathrm{~min}$, the amount of $\mathrm{NbN}$ remained approximately constant. On the contrary, during the process of austenitization at $1010^{\circ} \mathrm{C}$, no $\mathrm{NbN}$ particles dissolved into matrix. Starting from the fine and uniform grains, abnormal grain growth was observed after austenitizing at $1010^{\circ} \mathrm{C}$ for $960 \mathrm{~min}$ or at $1070^{\circ} \mathrm{C}$ for $180 \mathrm{~min}$ due to the heterogeneous distribution of $\mathrm{NbN}$ particles. The plot of grain size against $t_{A}$ indicated that the $\mathrm{NbN}$ particle with mean diameter of $117 \mathrm{~nm}$ and volume fraction of $3.1 \times 10^{-4}$ would be sufficient to inhibit the austenite grain size effectively. Finally, the EBSD measurements demonstrated that the high energy grain boundaries whose misorientation range is $20-45^{\circ}$ might be responsible for abnormal grain growth.
\end{abstract}

KEY WORDS: austenite grain growth; carbide dissolution; solution product formula; pinning effect; X12CrMoWVNbN10-1-1 steel.

\section{Introduction}

The use of X12CrMoWVNbN10-1-1 steel for manufacturing the high and middle pressure rotors of Ultra Supercritical Power Unit has demonstrated its superiority in high corrosion resistance, high temperature creep strength, good weldability, superior swelling resistance and excellent thermal property. ${ }^{1)}$ The rotors are commonly used in the extremely serious circumstances of high pressure and temperature requiring for the steel possessing comprehensive mechanical properties, which provides the impetus for its progressive development. The research on austenite grain growth is often of utmost significance, due to the tremendous effect of austenite grain size obtained from the subsequent cooling process on the microstructure and performance. The fine austenite grains contribute to the low stability of grain boundary which is a weakness for long-term creep strength of the steel. On the other hand, too large or heterogeneous austenite grains would cause the brittleness of steel. Besides, the ultrasonic inspection of the grain size is too difficult to carry out under such circumstance. ${ }^{2)}$ Therefore, it is necessary to study the austenite grain growth behavior so as to obtain desirable austenite grain size.

It is well known that small amounts of alloying elements

* Corresponding author: E-mail: gujf@sjtu.edu.cn

DOI: http://dx.doi.org/10.2355/isijinternational.54.1705 such as $\mathrm{V}, \mathrm{Nb}$ and $\mathrm{Ti}$ can significantly improve the overall mechanical properties through the precipitation of second phases and subsequent retarding the grain growth of austenite. Several theoretical models ${ }^{3-8)}$ have been proposed to interpret the pinning effect of precipitates on austenite grain growth. Most of them were based on Zener's concept and therefore deduced to a similar formulation. These models were established from the equilibrium between the driving force for grain growth and the pinning force of the precipitates exerting on the grain boundaries.

There have been several studies about the effect of carbonitrides on austenite grain size in some steels. Estay et $a l .{ }^{9)}$ followed the dissolution of carbide and the growth and shrinkage of austenite during the intercritical annealing of $\mathrm{Fe}-\mathrm{C}-\mathrm{Mn}$ dual phase steels. Considering the absence of detailed measurements of the relationship between particle size and density, Cuddy et al. ${ }^{10)}$ derived a phenomenological relation between steel composition and coarsening behavior of austenite grains, especially that between the grain coarsening temperature and the type and concentration of microalloying elements. They also proposed the factors that regulate particle dissolution. Gutiérrez et al. ${ }^{11)}$ investigated the influence of the austenitizing holding time $\left(t_{A}\right)$ and the heating rate to austenite on the development of a heterogeneous austenite grain size distribution in ASTM A213-T91 Steel at various austenitizing temperatures $\left(T_{A}\right)$, taking into account the size distribution of pinning particles. Shome et 
$a l .{ }^{12)}$ explained successfully the grain growth kinetics in the heat affected zone of HSLA-100 steel by tracking the change in the size of the dissolving particles. FU Liming et $a l .{ }^{13)}$ derived a kinetic equation for austenite grain growth concerning the mutual effect of $\mathrm{NbC}$ and $\mathrm{Nb}$ solute in low carbon Nb-microalloyed steels. However, all these previous works have been carried out over a rather short $t_{A}$ range (shorter than $360 \mathrm{~min}$ ) at different $T_{A}$. For the large forging (e.g. the maximum diameter is $\phi 1440 \mathrm{~mm}$ ), austenitization for a long time is necessary for the homogeneity in temperature. Moreover, most of the previous studies focused on the austenite grain size as a function of austenitizing temperature. Although Lizhan Han et al. ${ }^{14)}$ have already investigated the behavior of austenite grain growth of X12CrMoWVNbN10-1-1 steel, there have been no convincing evidences to explain the results. The relationship between carbonitride dissolution and isothermal austenite grain growth in this steel with longer holding time (up to $960 \mathrm{~min}$ ) has yet to be further resolved. Thus, it would be investigated in detail in present paper.

\section{Experimental}

The chemical composition of X12CrMoWVNbN10-1-1 steel is given in Table 1. The steel was received in the afterforging heat treated state, i.e. it was forged at a temperature range from to $1250^{\circ} \mathrm{C}$ and cooled in furnace from the forging temperature down to $690^{\circ} \mathrm{C}$, held at this temperature for $250 \mathrm{~h}$ and finally cooled in air down to room temperature.

In order to investigate the behavior of austenite grain growth, the heat treatments were performed in an electric resistance furnace. When the furnace reached a desired temperature, the samples with dimensions of $80 \mathrm{~mm} \times 40 \mathrm{~mm} \times$ $40 \mathrm{~mm}$ were put into it. They were soaked at a temperature in $1010^{\circ} \mathrm{C}-1200^{\circ} \mathrm{C}$ for different time ranging from $5 \mathrm{~min}$ to $960 \mathrm{~min}$ and then quenched in water. For a clear display of austenite grain size, additional heat treatment was done by holding at $700^{\circ} \mathrm{C}$ for about $40 \mathrm{~h}$ to facilitate the formation of carbonitrides decorating the grain boundaries. The microstructural characterization was performed on an optical microscope, Observer D1 m produced by Carl ZEISS. For eliminating the effect of decarburization and oxidation, the surface of samples was ground to remove $5 \mathrm{~mm}$ on the surface and then sectioned, mounted in resin, mechanically polished and etched using a mixture of $100 \mathrm{ml}$ distilled water, $2 \mathrm{~g}$ picric acid, $50 \mathrm{ml}$ sodium alkyl sulfonate, 6 drops of hydrochloric acid. The linear intercept method ${ }^{15,16)}$ in optical micrographs was employed to estimate the average austenite grain size.

In order to reveal the size of $\mathrm{NbN}$ particles and determine the grain boundary misorientations, the samples were observed and analyzed using scanning electron microscopy (SEM) and electron backscatter diffraction (EBSD) respectively. The EBSD measurement was carried out at an accelerating voltage of $20 \mathrm{kV}$ and step size of $0.15 \mathrm{um}$. If the

Table 1. Chemical composition of X12CrMoWVNbN10-1-1 steel in wt.\%.

\begin{tabular}{llllllllllllll}
\hline $\mathrm{C}$ & $\mathrm{Si}$ & $\mathrm{Mn}$ & $\mathrm{P}$ & $\mathrm{S}$ & $\mathrm{Cr}$ & $\mathrm{Mo}$ & $\mathrm{Ni}$ & $\mathrm{W}$ & $\mathrm{V}$ & $\mathrm{Al}$ & $\mathrm{N}$ & $\mathrm{Nb}$
\end{tabular}

$\begin{array}{llllllllllllll}0.11 & 0.08 & 0.41 & 0.008 & 0.004 & 10.35 & 1.00 & 0.80 & 1.03 & 0.18 & 0.02 & 0.051 & 0.040\end{array}$ misorientation showed a rotation angle less than $1^{\circ}$, the two points were interpreted to belong to the same lath and subgrain.

The phase identification of the carbonitrides was done on the extracted residues obtained by electrolytically dissolving the matrix in a solution consisting of 5\% glycerol, $1 \%$ citric acid monohydrate, $5 \%$ hydrochloric acid and methanol in volume fraction. The electric current was $0.7 \mathrm{~A}$ and the temperature was in the range of $-5^{\circ} \mathrm{C}$ to $0^{\circ} \mathrm{C}$. The residues extracted were identified by X-ray diffraction (XRD) performed on a D/max 2550X-ray diffractometer at $35 \mathrm{kV}$ and $200 \mathrm{~mA}$. Cu K $\alpha$ radiation was used and a $2 \theta$ range from 20 $120^{\circ}$ was step-scanned with a scanning speed $(2 \theta)$ of $3 \% \mathrm{~min}$.

The quantitative analyses of constituent elements in the carbonitrides were carried out in the following procedures. The extracted residues were filtered by a microporous membrane, followed by washing sequentially with an ethanol solution of citric acid $(10 \mathrm{~g} / \mathrm{L})$, an aqueous solution of citric acid $(10 \mathrm{~g} / \mathrm{L})$, an aqueous $\mathrm{NaOH}(10 \mathrm{~g} / \mathrm{L})$ solution, and finally distilled water. The membrane and precipitates were placed into a $250 \mathrm{~mL}$ beaker, and then $10 \mathrm{~mL} \mathrm{H}_{2} \mathrm{SO}_{4}$ and $20 \mathrm{~mL} \mathrm{HNO}_{3}$ were added into the beaker. This mixture was then heated with an electric cooker, until the membrane was completely dissolved, yielding a transparent homogeneous solution. After cooling the mixed solution, distilled water (20-30 mL) was added, followed by slow addition of a $4 \mathrm{~mL}$ citric acid solution $(500 \mathrm{~g} / \mathrm{L})$. Finally this mixed solution was transferred into a $100 \mathrm{ml}$ volumetric flask and distilled water was then used to dilute the solution until its volume reached $100 \mathrm{~mL}$. Inductively coupled plasma emission spectrometer (ICP-AES), ICAP-6300, provided by Thermo Company, was then employed to measure and determine the content of each alloying elements in the solution. In addition, the content of nitrogen in the precipitates was measured according to the international standard UDC 669.14/.15:543.24:546.17, namely, "The volumetric method for the determination of nitrogen content after distillation separation".

The size distribution of extracted particles was measured on a Small Angle X-ray Scattering (SAXS) instrument, X'Pert Pro MPD produced by PANalytical Company, at $40 \mathrm{kV}$ and $40 \mathrm{~mA} . \mathrm{Cu} \mathrm{K}$ radiation and slits $(1 / 32,1 / 16,1 / 4$, $0.04 \mathrm{~mm}$ ) were used. The shape of particles was assumed to

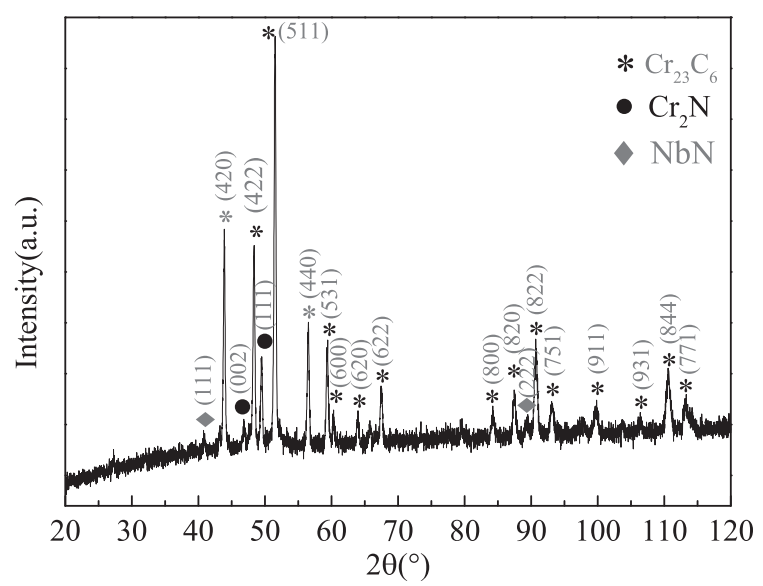

Fig. 1. XRD patterns of the extracted residues from the as-received steel. 
be a sphere.

Transmission electron microscopy (TEM) observations and energy dispersive spectrometry (EDS) analyses were performed on a JEM-2100F instrument at operating voltage of $200 \mathrm{kV}$ to identify the precipitates as well. Foils for TEM observation were prepared from the center of the austenitized samples, mechanically ground from 300 um down to $40 \mathrm{um}$, cutting into $\phi 3 \mathrm{~mm}$ discs. These foils were subsequently electropolished at $-25^{\circ} \mathrm{C}$ with an operating voltage of $75 \mathrm{~V}$ using a MTP-1A twinjet polisher in a solution containing $95 \%$ acetic acid and 5\% perchloric acid.

\section{Results}

\subsection{Characterization of the Precipitates in As-received Steel}

The XRD pattern (Fig. 1) shows the presence of $\mathrm{Cr}_{23} \mathrm{C}_{6}$, $\mathrm{Cr}_{2} \mathrm{~N}$ and $\mathrm{NbN}$ in as-received state. Figures $2-4$ are the results of TEM micrographs showing the morphology of the precipitates and their constituent elements contained. From Fig. 2(a), it can be seen that the precipitated phase $\mathrm{M}_{23} \mathrm{C}_{6}$ is easily observed and identified by its selected electron diffraction pattern (Fig. 2(b)) and $\mathrm{M}=\mathrm{Cr}$ (the main constituent element), Fe, Mo, etc. as indicated by the EDS spectrum in
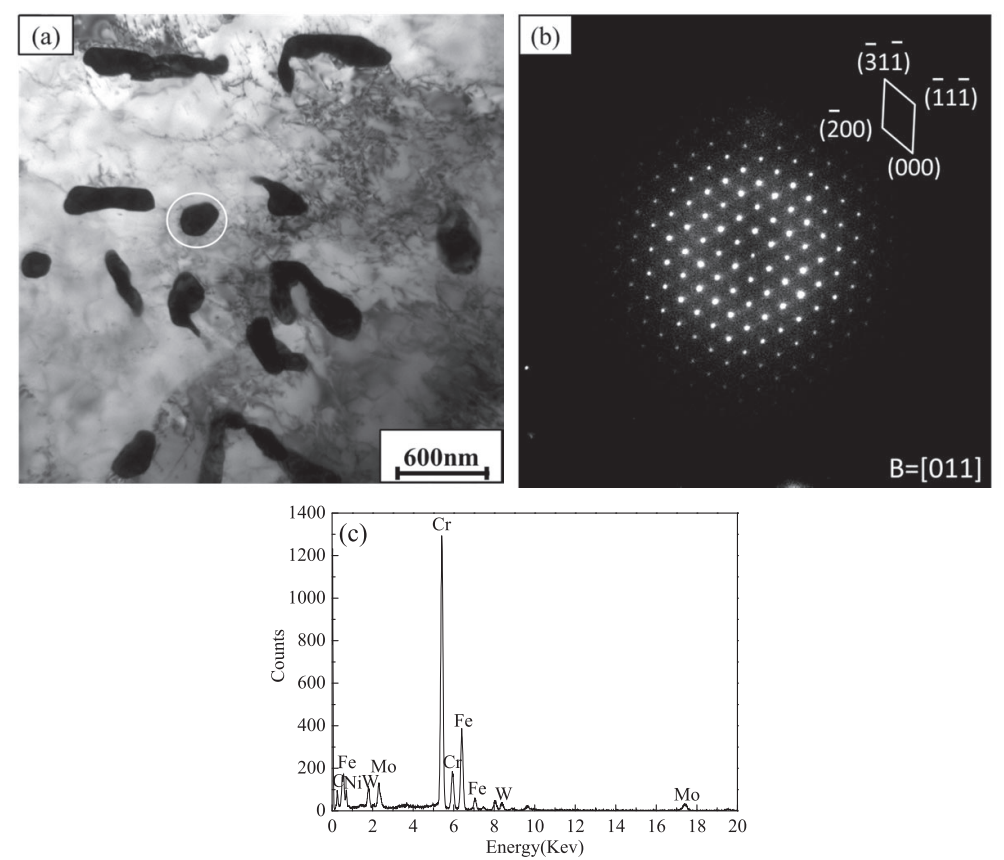

Fig. 2. (a) TEM bright field (BF) micrograph of as-received steel, showing the $\mathrm{M}_{23} \mathrm{C}_{6}$ precipitate particles, (b) and (c) are the SAED pattern and EDS spectrum respectively, taken from the circled particle in (a).

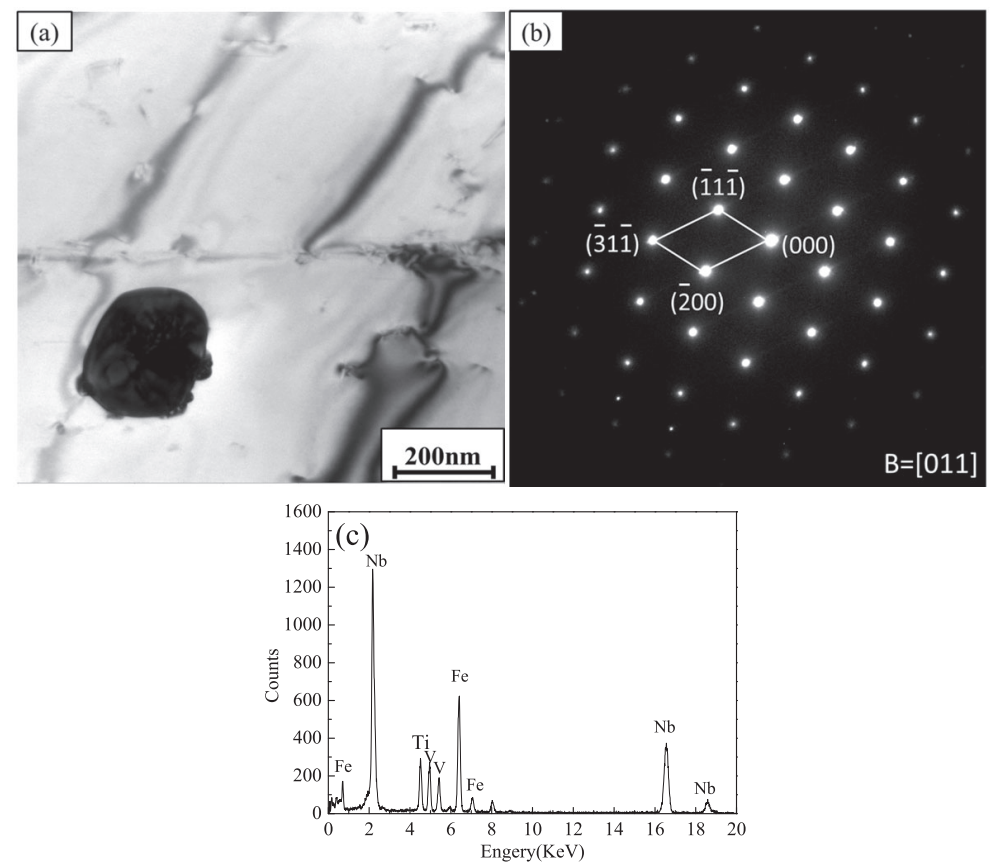

Fig. 3. (a) TEM BF micrograph showing a NbN particle in as-received steel with corresponding (b) SAED pattern and (c) EDS spectrum. 

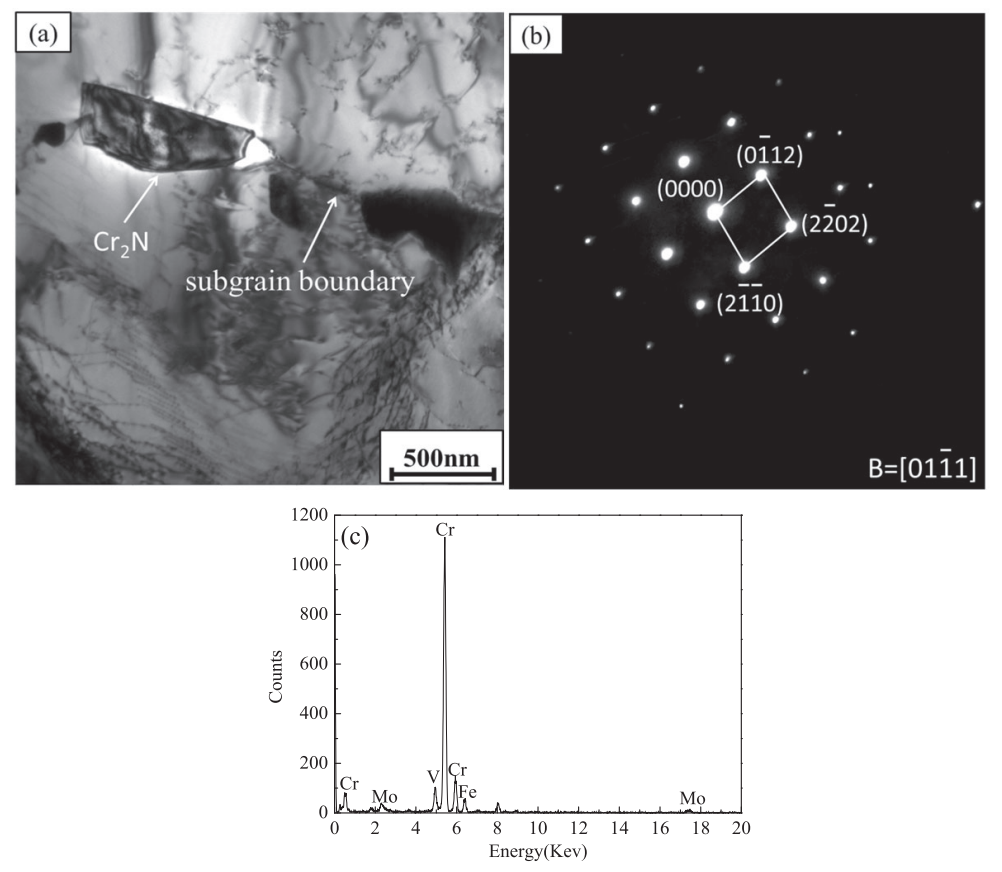

Fig. 4. (a) TEM BF micrograph showing $\mathrm{Cr}_{2} \mathrm{~N}$ particle existing at subgrain boundaries in as-received steel with corresponding (b) SAED pattern and (c) EDS spectrum.

Fig. 2(c).

The precipitate $\mathrm{NbN}$ was also confirmed with a size of about $300 \mathrm{~nm}$ in diameter (Fig. 3). However, most of them are smaller than this size as seen in Fig. 5. Besides, the presence of $\mathrm{Cr}_{2} \mathrm{~N}$ was also recognized in as-received steel, forming along the subgrain boundaries (Fig. 4). Therefore, the as-received steel contains the ferritic matrix with numerous $\mathrm{Cr}_{23} \mathrm{C}_{6}$ and small amounts of $\mathrm{NbN}$ and $\mathrm{Cr}_{2} \mathrm{~N}$, as consistent with that report in Ref. 17).

\subsection{Growth Behavior of Austenite Grains}

The optical micrographs of grain size in different austenitized states are shown in Fig. 6. In Figs. 6(b) and 6(c), several grains are found to have grown abnormally compared to the others nearby. This stage can be considered as a 'heterogeneous', or sometimes called 'abnormal' grain growth (AGG). As $t_{A}$ increased, normal grains were being continuously consumed by abnormal grains and even completely disappeared after $1070^{\circ} \mathrm{C} / 960 \mathrm{~min}$, as seen in Fig. 6(d). In view of this, it is reasonable to expect that AGG is a transient phenomenon occurring in grain size controlled materials under specific heat treatment conditions. However, no AGG is observed for austenitizing at even higher $T_{A}$, e.g. $1200^{\circ} \mathrm{C}$ (Figs. 6(e) and 6(f)). Figure 7 shows the dependence of average austenite grain size on $t_{A}$ at various temperatures. It is shown that the austenite grains grow slowly at $1010^{\circ} \mathrm{C}$. However, at $1070^{\circ} \mathrm{C}$, the austenite grain growth rate is very slow in the beginning period but an abrupt increase in austenite grain size was observed after $120 \mathrm{~min}$. Instead, there is always a rapid growth rate of austenite grain size when austenitized at $1200^{\circ} \mathrm{C}$.

\section{3. $\quad$ Extracted Particles in Austenitized Steel}

The extracted precipitates from the steel austenitized at $1070^{\circ} \mathrm{C}$ are mainly $\mathrm{NbN}$ as identified by XRD (Fig. 8), although a trace amount of $\mathrm{Cr}$-rich precipitates was detected at its very beginning (e.g. $t_{A}=15 \mathrm{~min}$ ) and also confirmed

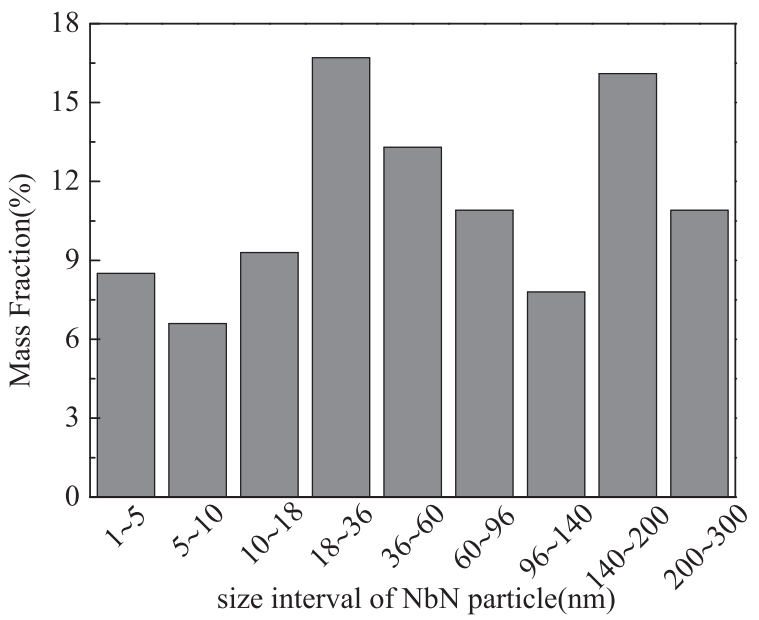

Fig. 5. The size distribution of $\mathrm{NbN}$ particles in after-forging heat treated steel.

by SEM (Fig. 9). The chemical analyses of extracted particles reveal that the main constituent element is $\mathrm{Nb}$ in such precipitates as shown in Table 2. No $\mathrm{Cr}$ was detected in the residues from the samples austenitized at $1070^{\circ} \mathrm{C}$ for longer than $60 \mathrm{~min}$ or at $1200^{\circ} \mathrm{C}$ for longer than $15 \mathrm{~min}$, suggesting that the $\mathrm{Cr}_{23} \mathrm{C}_{6}$ has almost completely dissolved under these conditions, and only $\mathrm{NbN}$ left. This result falls in agreement with Gutiérrez et al. ${ }^{11)}$ who reported that $\mathrm{Cr}$-rich $\mathrm{M}_{23} \mathrm{C}_{6}$ carbide dissolved completely after $15 \mathrm{~min}$ at $1060^{\circ} \mathrm{C}$ or $1080^{\circ} \mathrm{C}$ with the heating rate of $1{ }^{\circ} \mathrm{C} / \mathrm{s}$ or $50^{\circ} \mathrm{C} / \mathrm{s}$.

Table 2 also shows that $\mathrm{Nb}$-content of the extracted particles decreases slowly with the increasing $t_{A}$ when austenitized at $1070^{\circ} \mathrm{C}$, indicating that the dissolution of $\mathrm{NbN}$ did occur. However, when $t_{A}$ gets over $360 \mathrm{~min}, \mathrm{Nb}$ content seems further unchanged up to $960 \mathrm{~min}$, implying that $\mathrm{NbN}$ did not dissolve any longer. Comparing with the data of $\mathrm{Nb}$ after austenitization, partial $\mathrm{NbN}$ dissolves further with the increasing $T_{A}$ from $1070^{\circ} \mathrm{C}$ to $1200^{\circ} \mathrm{C}$ as its mass fraction 

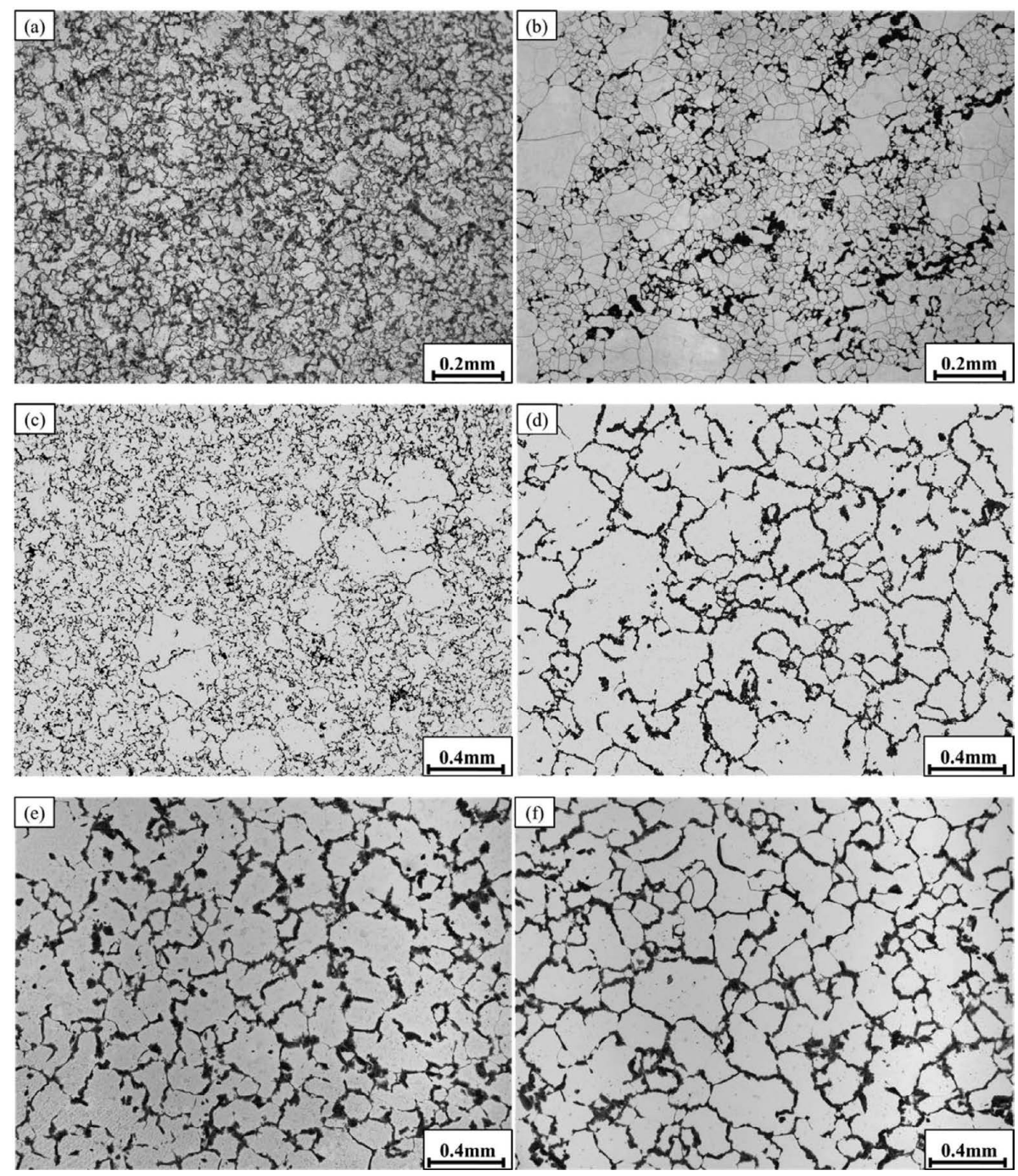

Fig. 6. Optical micrographs of the steel austenitized at $T_{A} / t_{A}$ : (a) $1010^{\circ} \mathrm{C} / 360 \mathrm{~min}$, (b) $1010^{\circ} \mathrm{C} / 960 \mathrm{~min}$, (c) $1070^{\circ} \mathrm{C} /$ $180 \mathrm{~min}$, (d) $1070^{\circ} \mathrm{C} / 960 \mathrm{~min}$, (e) $1200^{\circ} \mathrm{C} / 5 \mathrm{~min}$, (f) $1200^{\circ} \mathrm{C} / 60 \mathrm{~min}$, and then held at $700^{\circ} \mathrm{C}$ for about $40 \mathrm{~h}$ and finally quenched in water.

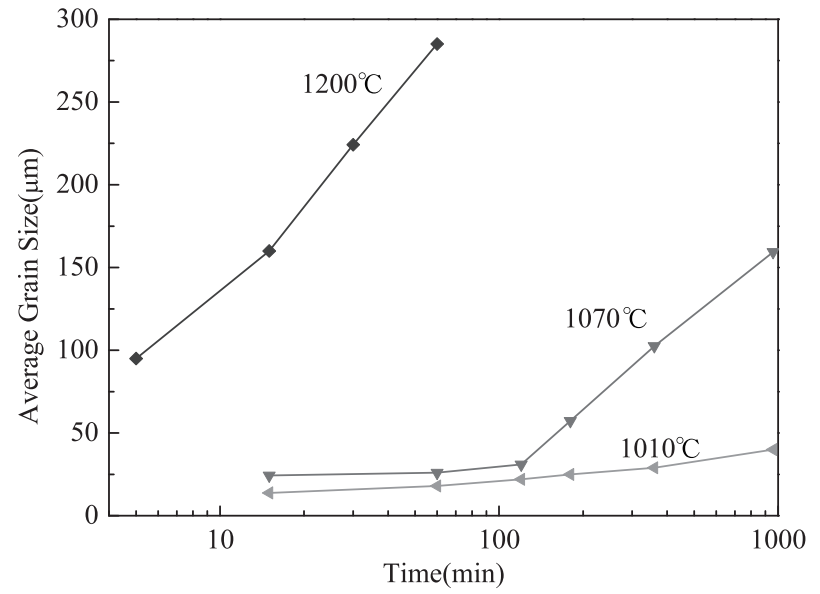

Fig. 7. Average austenite grain size as a function of holding time at different austenitization temperatures.

of $\mathrm{Nb}$ decreases correspondingly. While, $\mathrm{NbN}$ does not dissolve during austenitization at $1010^{\circ} \mathrm{C}$ for $960 \mathrm{~min}$ because of the same content of $\mathrm{Nb}(0.04 \mathrm{wt} . \%)$ in extracted particles detected in the after-forging heat treated state. The mean particle size (average of 150 particles for each) under dif-

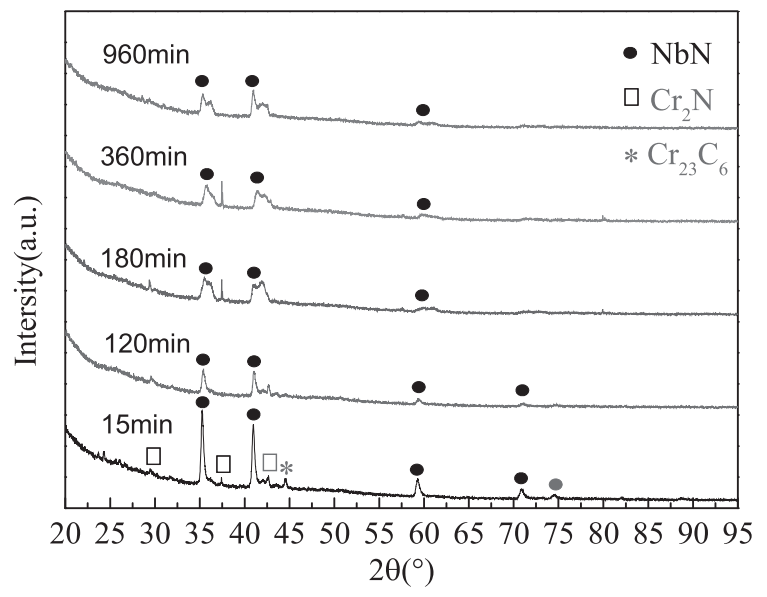

Fig. 8. XRD patterns of extracted residues from the samples austenitized at $1070^{\circ} \mathrm{C}$ for different $t_{A}$.

ferent austenitization conditions was measured with SEM observations in Table 3, showing that the size of particles increases with $t_{A}$. 

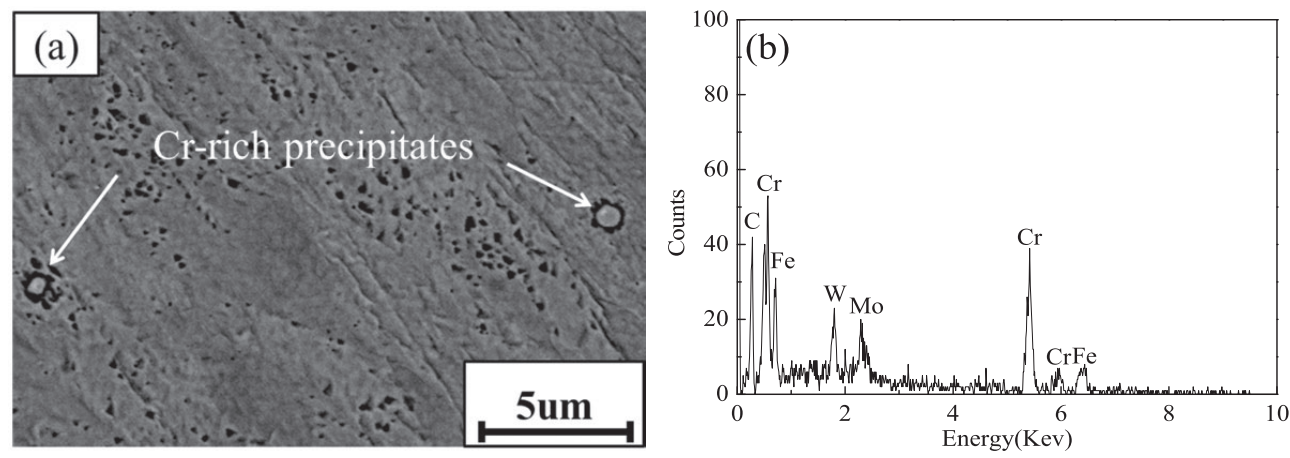

Fig. 9. Cr-rich precipitates in steel austenitized at $1070^{\circ} \mathrm{C}$ for $15 \mathrm{~min}$ (a) SEM micrograph (b) EDS spectrum of Cr-rich precipitates.

Table 2. The elements contained in extracted particles in steels under different conditions (in wt.\%).

\begin{tabular}{cccc}
\hline States & $\mathrm{Cr}$ & $\mathrm{Nb}$ & $\mathrm{N}$ \\
\hline As-received & 1.408 & 0.04 & 0.051 \\
$1010^{\circ} \mathrm{C} / 960 \mathrm{~min}$ & 0.093 & 0.04 & 0.0097 \\
$1070^{\circ} \mathrm{C} / 15 \mathrm{~min}$ & 0.056 & 0.032 & 0.0047 \\
$1070^{\circ} \mathrm{C} / 60 \mathrm{~min}$ & - & 0.031 & 0.0046 \\
$1070^{\circ} \mathrm{C} / 120 \mathrm{~min}$ & - & 0.029 & 0.0044 \\
$1070^{\circ} \mathrm{C} / 180 \mathrm{~min}$ & - & 0.028 & 0.0043 \\
$1070^{\circ} \mathrm{C} / 360 \mathrm{~min}$ & - & 0.027 & 0.0040 \\
$1070^{\circ} \mathrm{C} / 960 \mathrm{~min}$ & - & 0.027 & 0.0039 \\
$1200^{\circ} \mathrm{C} / 5 \mathrm{~min}$ & 0.011 & 0.0063 & 0.0013 \\
$1200^{\circ} \mathrm{C} / 15 \mathrm{~min}$ & - & 0.006 & 0.0012 \\
$1200^{\circ} \mathrm{C} / 60 \mathrm{~min}$ & - & 0.0058 & 0.0012 \\
\hline
\end{tabular}

Note: “-” represents not detected.

Table 3. The volume fraction and mean radius of $\mathrm{NbN}$ in steel after various austenitization conditions.

\begin{tabular}{ccc}
\hline States & Volume fraction, $\times 10^{-4}$ & Mean Diameter, $\mathrm{nm}$ \\
\hline $1010^{\circ} \mathrm{C} / 960 \mathrm{~min}$ & 4.15 & 119 \\
$1070^{\circ} \mathrm{C} / 15 \mathrm{~min}$ & 3.21 & 89 \\
$1070^{\circ} \mathrm{C} / 60 \mathrm{~min}$ & 3.11 & 98 \\
$1070^{\circ} \mathrm{C} / 120 \mathrm{~min}$ & 3.10 & 117 \\
$1070^{\circ} \mathrm{C} / 180 \mathrm{~min}$ & 2.90 & 168 \\
$1070^{\circ} \mathrm{C} / 360 \mathrm{~min}$ & 2.80 & 221 \\
$1070^{\circ} \mathrm{C} / 960 \mathrm{~min}$ & 2.80 & 300 \\
\hline
\end{tabular}

\section{Discussion}

\subsection{Effect of Austenitizing Temperature on the Disso- lution of $\mathbf{N b N}$}

For the dissolution of a carbonitride MX into its soluble components, $\mathrm{MX} \Leftrightarrow[\mathrm{M}]+[\mathrm{X}]$, the solubility product can be expressed by

$$
\log [\mathrm{M}][\mathrm{X}]=A-B / T
$$

where $A$ and $B$ are constants known from published solubility data, $T$ is the absolute temperature in $\mathrm{K},[\mathrm{M}]$ and $[\mathrm{X}]$ are the equilibrium concentration (wt.\%) of $\mathrm{M}$ and $\mathrm{X}$ in matrix.
Table 4. Solubility products ${ }^{*}$ for $\mathrm{NbN}$ in steel.

\begin{tabular}{cccccc}
\hline Compound & Metal & Non-metal & \multicolumn{1}{c}{$\mathrm{A}$} & $\mathrm{B}$ & Reference \\
\hline $\mathrm{NbN}(1)$ & $\mathrm{Nb}$ & $\mathrm{N}$ & 2.8 & 8500 & {$[18]$} \\
$\mathrm{NbN}(2)$ & $\mathrm{Nb}$ & $\mathrm{N}$ & 4.04 & 10230 & {$[19]$} \\
$\mathrm{NbN}(3)$ & $\mathrm{Nb}$ & $\mathrm{N}$ & 3.7 & 10800 & {$[20]$} \\
$\mathrm{NbN}_{0.87}(4)$ & $\mathrm{Nb}$ & $\mathrm{N}_{0.87}$ & 2.86 & 7927 & {$[21]$} \\
$\mathrm{NbN}(5)$ & $\mathrm{Nb}$ & $\mathrm{N}$ & 4.2 & 10000 & {$[22]$} \\
\hline
\end{tabular}

*The data refer to $\mathrm{M}_{\mathrm{a}} \mathrm{X}_{\mathrm{b}}$ following the Eq. (2) with concentrations measured in mass fraction (wt.\%) and $\mathrm{T}$ in $\mathrm{K}$.

$$
\log \left([\mathrm{M}]^{\mathrm{a}}[\mathrm{X}]^{b}\right)=\mathrm{A}-\mathrm{B} / \mathrm{T}
$$

Due to the crucial significance of the equilibrium solubility product formulae (SPF) in relevant theoretical work and practical application, the bulk of work has already been carried on to derive the formulae for common carbonitrides in steels by experiment or thermodynamics derivation. In the light of the difference in experiments and assumed derivation conditions, the calculated results from the different SPF for the same precipitated phase have an enormous range. There are several SPF proposed for $\mathrm{NbN}$ in austenite as listed in Table 4. It is essential to select the suitable SPF for practical application.

When the steel reaches an equilibrium state at $1070^{\circ} \mathrm{C}$, the calculated solubility products of $\mathrm{Nb}$ and $\mathrm{N}$ in mass fraction with SPF (1)-(5) are $2.96 \times 10^{-4}, 2.65 \times 10^{-4}, 4.55 \times 10^{-5}$, $9.07 \times 10^{-4}$ and $5.68 \times 10^{-4}$ respectively. However, according to the measured data shown in Table 2 the maximum solubility product of $\mathrm{Nb}$ and $\mathrm{N}\left(1070^{\circ} \mathrm{C} / 960 \mathrm{~min}\right)$ is $6.123 \times 10^{-4}$. The results calculated with SPF (1), (2), (3) and (5) are smaller than the experimental one, indicating that $\mathrm{Nb}$ and $\mathrm{N}$ can not be dissolved in matrix so much when the samples were austenitized at $1070^{\circ} \mathrm{C}$, but actually they did. Therefore, SPF (1), (2), (3) and (5) can be excluded. On the other hand, the solubility product calculated with SPF (4) is larger than that measured in present experiment, which indicates that $\mathrm{Nb}$ and $\mathrm{N}$ are not saturated in matrix when the samples are austenitized at $1070^{\circ} \mathrm{C}$. Based on the chemical composition of the as-received material (Table 1), the complete solution temperature of $\mathrm{NbN}$ calculated with the SPF (4) is about $1200^{\circ} \mathrm{C}$, which is closed to that reported in Ref. 23). It is worth to note that it is a value in equilibrium state. Although $\mathrm{NbN}$ was still observed in the sample austenitized at $1200^{\circ} \mathrm{C}$ for $90 \mathrm{~min}$ as shown in Fig. 10, signifying that 

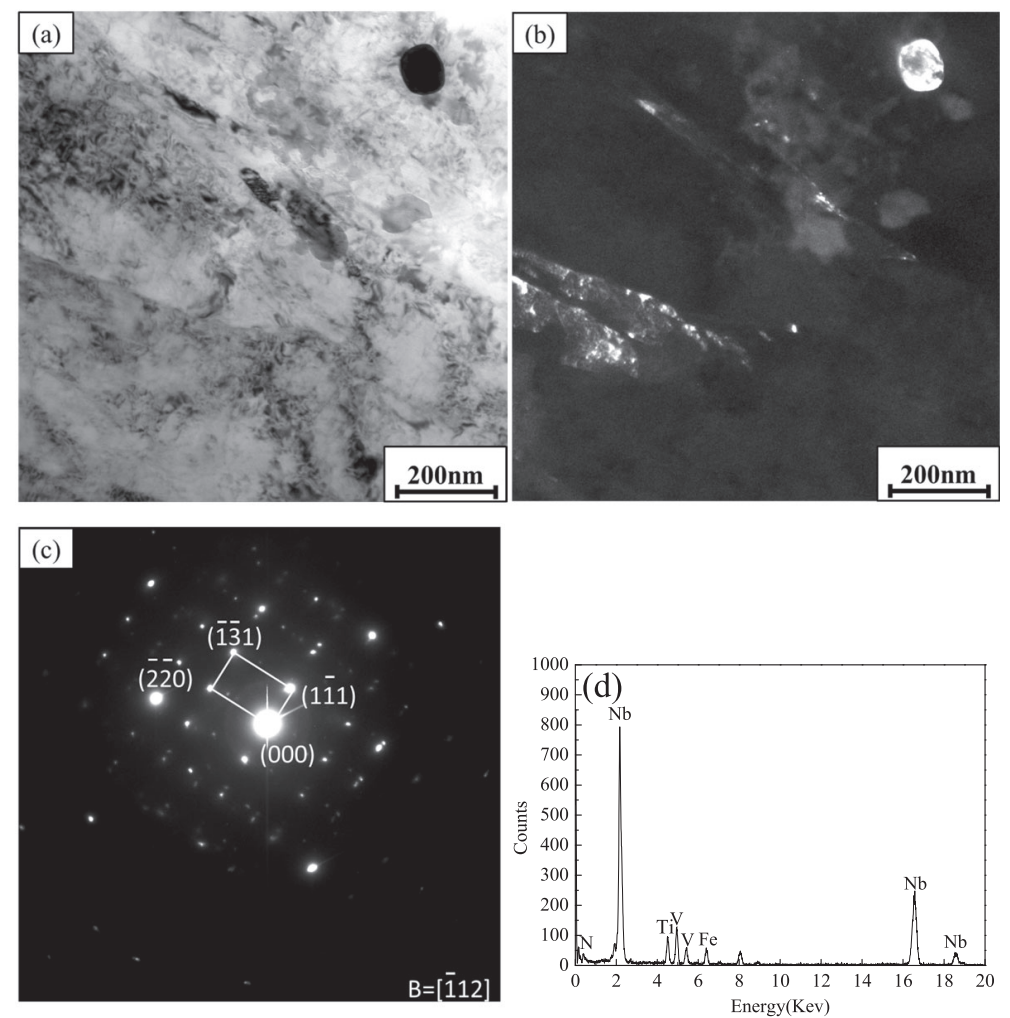

Fig. 10. (a) TEM bright field (BF) micrograph of the sample after austenitization at $1200^{\circ} \mathrm{C}$ for 90 min, showing a NbN particle, (b) dark field (DF) micrograph of NbN particle, (c) the SAED pattern and (d) EDS spectrum taken from the particle.

the equilibrium state did not reach under such a condition. The complete solution temperature of $\mathrm{NbN}\left(1200^{\circ} \mathrm{C}\right)$ is higher than $1070^{\circ} \mathrm{C}$ and this is the reason why there is still room in matrix to allow $\mathrm{Nb}$ and $\mathrm{N}$ dissolution. However, after austenitization at $1070^{\circ} \mathrm{C}$ for 360 min the amount of $\mathrm{NbN}$ remains unchanged.

As discussed above, SPF (4) is suitable for the present work. Theoretically, the carbonitrides exhibiting the strongest effect on grain growth control should be the most stable, i.e. the one with the highest solution temperature. ${ }^{24)}$ The absence of $\mathrm{Cr}_{23} \mathrm{C}_{6}$ at $1070^{\circ} \mathrm{C}$ implies that such an austenitizing temperature is higher than that required to completely dissolve it. Therefore, the presence of $\mathrm{Cr}_{23} \mathrm{C}_{6}$ must have little influence on grain growth.

\subsection{Calculation of Volume Fraction of Precipitate}

Supposing the concentration of the elements $\mathrm{M}$ and $\mathrm{X}$ in $\mathrm{MX}_{\mathrm{x}}(\mathrm{wt} . \%)$ is $M$ and $X$ respectively, when the investigated temperature $T$ is lower than the complete solution temperature, the two requirements should be considered, i.e. the SPF and the stoichiometric ratio of $\mathrm{MX}_{\mathrm{x}}$.

$$
\begin{gathered}
{[M][X]^{x}=10^{A-B / T}} \\
\frac{M-[M]}{X-[X]}=\frac{A_{M}}{x A_{X}} .
\end{gathered}
$$

Where $A_{M}$ and $A_{X}$ are the relative atomic mass of $\mathrm{M}$ and $\mathrm{X}$ respectively. Combining the Eqs. (3) and (4), [M] and [X] at temperature $T$ can be calculated. Then, the volume fraction of $\mathrm{MX}_{\mathrm{x}}$ in this steel, $f$, at this temperature can be obtained:

$$
\begin{aligned}
f & =(M-[M]+X-[X]) \times \frac{d_{F e}}{100 d_{M X}} \\
& =(M-[M]) \times \frac{A_{M}+x A_{X}}{A_{M}} \times \frac{d_{F e}}{100 d_{M X}}
\end{aligned}
$$

where $d_{F e}=7.8 \mathrm{~g} / \mathrm{cm}^{3}, d_{N b N}=8.371 \mathrm{~g} / \mathrm{cm}^{3}$ are the density of $\mathrm{Fe}$ and $\mathrm{NbN}$ respectively. ${ }^{25,26)}$ From this equation, it is obvious that the volume fraction of $\mathrm{NbN}$ is dependent on the amount of $\mathrm{Nb}$ contained in $\mathrm{NbN}$ particles. Therefore, the volume fraction of $\mathrm{NbN}$ after austenitization at $1070^{\circ} \mathrm{C}$ can be calculated, based on the data in Table 2 and Eq. (5), as listed in Table 3. The magnitude order of volume fraction of $\mathrm{NbN}$ is $10^{-4}$, which is consistent with the result of Ref. 27).

\subsection{Austenite Grain Growth Behavior}

When the initial austenite grains are fine and uniform, the grain boundary area would be large and leads to a high total interfacial energy. From the thermodynamics point of view, the higher interfacial energy leads to the more unstable interface and tends to be lowered through the coalescence of fine grains. The theory of grain growth is based on the grain boundary interfacial free energy as the driving force. The driving force leading to grain boundary migration resulting in the grain growth is determined not only by the physical constants characteristic of the substances in bulk, but also by the shape and dimensions of the individual grains. ${ }^{28)}$ In the present case, the presence of $\mathrm{NbN}$, acting as barriers, impedes the grain boundary migration. In other words, the grain growth would not occur under the condition where the matrix grain boundaries are strongly pinned by $\mathrm{NbN}$ particles. This is the reason why the autenite grains grow so 
slowly at $1010^{\circ} \mathrm{C}$ for $15-960 \mathrm{~min}$ or at $1070^{\circ} \mathrm{C}$ for $15-$ $120 \mathrm{~min}$. Meanwhile, it also suggests that it is the $\mathrm{NbN}$ that controls the austenite grain size effectively as expected and these particles with $117 \mathrm{~nm}$ in diameter and $3.1 \times 10^{-4}$ in volume fraction are sufficient to restrict the growth of the matrix grains in this steel. As the Fig. 11 shows, the growing trend of $\mathrm{NbN}$ particles is almost the same as that of austenite grains and the $\mathrm{NbN}$ particles coarsen rapidly when AGG occurs. This means that the relatively larger $\mathrm{NbN}$ particles may also grow at the expense of the smaller ones. This is called Ostwald ripening. ${ }^{29)}$ Gladman ${ }^{4)}$ pointed out the coalescence of the precipitate to a size in excess of the critical value permits the grain growth. Alternatively, the prolongation of holding time at $1070^{\circ} \mathrm{C}$ and the increase in temperature (from $1070^{\circ} \mathrm{C}$ to $1200^{\circ} \mathrm{C}$ ) would cause more

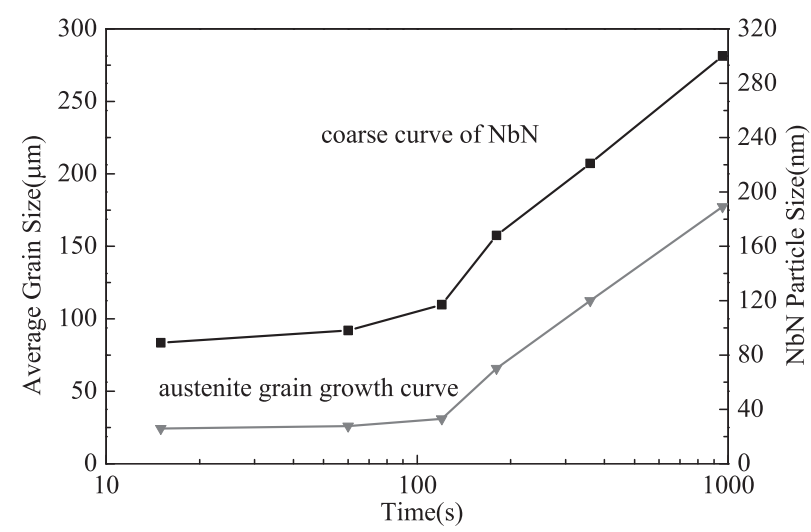

Fig. 11. The size of austenite grain and $\mathrm{NbN}$ particle size vs. austenitizing time at $1070^{\circ} \mathrm{C}$ dissolution of $\mathrm{NbN}$ particles. The maximum volume fraction of undissolved $\mathrm{NbN}$ calculated at $1200^{\circ} \mathrm{C}$ is $6.64 \times 10^{-5}$, which is much less than that at $1070^{\circ} \mathrm{C}$. According to the pinning theory, ${ }^{5)}$ the pinning force is proportional to the volume fraction of particles, and varies inversely as their mean size, i.e. the larger particles with little volume fraction will somehow result in the weakening of pinning effect. The grain boundaries whose driving force is larger than the pinning force migrate faster than any other grain boundaries, i.e. when the driving force reaches a critical value, the grain boundaries break away from the pinning atmosphere and undergo a discontinuous jump from dragged migration in the low-velocity to free migration in the high velocity. ${ }^{30}$ ) Therefore, the abrupt increase of austenite grain size at $1070^{\circ} \mathrm{C}$ after $120 \mathrm{~min}$ or at $1200^{\circ} \mathrm{C}$ can be attributed to the weak pinning force caused by coarsening of $\mathrm{NbN}$ and its decrease of volume fraction. In other words, the instability of the precipitates and their dissolution with increasing $T_{A}$ are accompanied by rapid grain growth.

The occurrence of AGG (Figs. 6(b) and 6(c)) can be explained by the $\mathrm{NbN}$ heterogeneity, e.g. non-uniform distribution, different size and interparticle distance. AGG was commonly observed occurring in microalloyed steels. ${ }^{31-34)}$ At a higher temperature $\left(1200^{\circ} \mathrm{C}\right)$, the dissolution of $\mathrm{NbN}$ precipitates allows more grains to grow and results in a form of grain growth that can be regarded as normal. This situation is also descriptive of the conditions existing in steel welding, since the heat affected zone(HAZ) austenite grains can grow fairly unhindered by second phase particles due to the high peak temperatures involved. ${ }^{35-37)}$ However, many researchers did not give any clear-cut answer to the question that which type of grain boundary is responsible for the
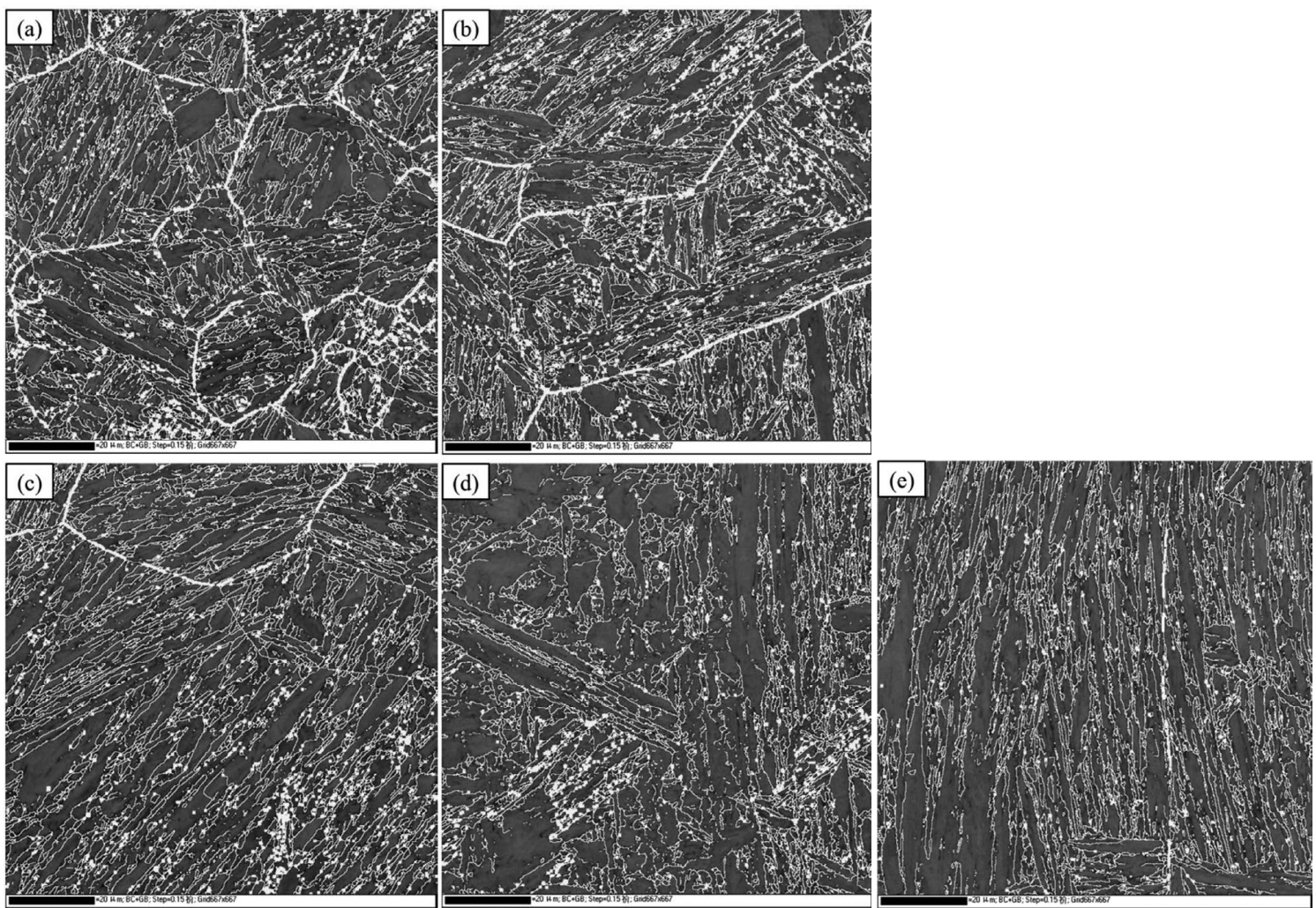

Fig. 12. EBSD analyses of grain boundaries in the steel austenitized at $1070^{\circ} \mathrm{C}$ for (a) $15 \mathrm{~min}$ (b) $120 \mathrm{~min}$ (c) $180 \mathrm{~min}(\mathrm{~d})$ $360 \mathrm{~min}$ and (e) $960 \mathrm{~min}$. The red curves represent the grain boundaries having different misorientations in the range of $20-45^{\circ}$. 


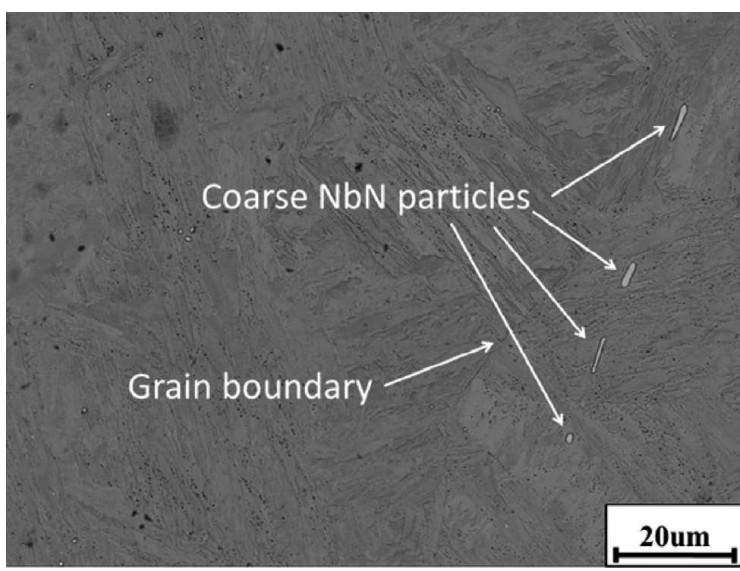

Fig. 13. SEM micrograph of $\mathrm{NbN}$ particles in the steel austenitized at $1070^{\circ} \mathrm{C}$ for $3 \mathrm{~h}$.

AGG. Although a lot of work has been published on the possible role of $\sum 9$ and other coincidence site lattice (CSL) boundaries on $\mathrm{AGG}^{38-41)}$ this role has not been confirmed satifactorily. Rajmohan et $a l^{42)}$ drew the conclusion that CSL boundaries are not responsible for the AGG in Fe$3 \% \mathrm{Si}$ steel through computer experiment results. Rollett and Grest ${ }^{43,44)}$ demonstrated that variable grain boundary mobility and energy can lead to AGG. Monte Carlo's simulations have confirmed that two different conditions may initiate AGG. Firstly, anisotropy in the grain boundary energy can lead to rapid growth of grains having boundary energies much higher than the average. Secondly, AGG may arise from anisotropy in the grain boundary mobility. ${ }^{44-47)}$ Based on electron back scattered pattern (EBSP) measurements and Monte Carlo simulations, ${ }^{48-50)}$ Hayakawa et al. stressed the importance of systematic unpinning of precipitates on the high energy grain boundaries that are responsible for AGG. Meanwhile, they also argued that high energy grain boundaries whose misorientation range is in $20-45^{\circ}$ play a role in AGG. A similar conclusion was also derived by Titorov $^{51,52)}$ from experiment and grain misorientation analyses of pole figures.

In the present study, the occurrence of AGG can also be explained with such conclusion by EBSD measurement (Fig. 12). The process of grain boundary migration does not take place through a jump of an atom from one grain to another grain, but through the exchange of vacancies. ${ }^{53-55)}$ The high-energy boundary is more capable to absorbing and emitting vacancies ${ }^{56}$ and the number of vacancies is related to the disorder in the grain boundary structure. A high-energy boundary has a more disordered structure, and therefore a higher number of vacancies and dislocations should contribute to a high mobility. On the other hand, an easier grain boundary diffusion along the high-energy boundary facilitates the diffusion-controlled coarsening of precipitates and therefore contributes to the weakening of the pinning effect. The coarse precipitates are frequently found inside large grains (Fig. 13). This fact supports the assumption that precipitates coarsen at the high-energy boundary. Following this argument, it is reasonable to assume that the high-energy boundaries have higher mobility than the low-energy boundary and thus move earlier. The experimental findings ${ }^{57)}$ also demonstrated that the growing large grain has a high number of general high-energy grain boundaries. Additionally,
Table 5. EBSD-measured fraction of boundaries with different misorientation angles in the samples after austenitization at $1070^{\circ} \mathrm{C}$ for different $t_{A}$.

\begin{tabular}{rccc}
\hline$t_{A}(\mathrm{~min})$ & $\begin{array}{c}\text { Fraction of the } \\
\text { high-energy boundary } \\
\text { with misorientation } \\
\text { ranging from } \\
20^{\circ} \text { to } 45^{\circ}(\%)\end{array}$ & $\begin{array}{c}\text { Fraction of the } \\
\text { boundaries with } \\
\text { misorientation lower } \\
\text { than } 20^{\circ}(\%)\end{array}$ & $\begin{array}{c}\text { Fraction of the } \\
\text { boundaries with } \\
\text { misorientation } \\
\text { higher than } 45^{\circ}(\%)\end{array}$ \\
\hline 15 & 5.68 & 77.82 & 15.53 \\
120 & 3.84 & 79.19 & 15.46 \\
180 & 2.93 & 81.46 & 14.65 \\
360 & 2.11 & 82.22 & 14.65 \\
960 & 0.68 & 81.66 & 16.66 \\
\hline
\end{tabular}

from the viewpoint of thermodynamics, the high energy of grain boundary is more unstable and tends to be lowered during the process of austenitization. Thus, the high-energy boundary is consumed for AGG. This is the reason why the fraction of grain boundaries having different misorientations in the range of $20-45^{\circ}$, as indicated by the red curves in Fig. 12 , gets smaller with increasing time during austenitization at $1070^{\circ} \mathrm{C}$, as shown in Table $\mathbf{5}$.

\section{Conclusions}

(1) For the X12CrMoWVNbN10-1-1 steel investigated, in its after-forging heat treated state the carbonitrides existed are mainly $\mathrm{Cr}_{23} \mathrm{C}_{6}$ and trace amounts of $\mathrm{NbN}$ and $\mathrm{Cr}_{2} \mathrm{~N}$ detected by XRD and TEM. The complete dissolution of $\mathrm{Cr}_{23} \mathrm{C}_{6}$ and $\mathrm{Cr}_{2} \mathrm{~N}$ finishes after austenitization at $1070^{\circ} \mathrm{C}$ for $60 \mathrm{~min}$ or at $1200^{\circ} \mathrm{C}$ for $15 \mathrm{~min}$, and only NbN left. Moreover, the dissolution of $\mathrm{NbN}$ occurs with the extending of austenitizing holding time at $1070^{\circ} \mathrm{C}$. However, when the time is over $360 \mathrm{~min}$, the amount of $\mathrm{NbN}$ remains unchanged. However, during the process of austenitization at $1010^{\circ} \mathrm{C}$, no $\mathrm{NbN}$ particles dissolved into matrix.

(2) The solubility product formula (SPF) of $\mathrm{NbN}$ suitable for the present study is $\lg \left\{[N b][N]^{0.87}\right\}_{\gamma}=2.86-7927 /$ $T$. The magnitude order of volume fraction of $\mathrm{NbN}$ is $10^{-4}$.

(3) The austenite grains grow slowly at $1010^{\circ} \mathrm{C}$ and at $1070^{\circ} \mathrm{C}$ when $t_{A}$ is shorter than $120 \mathrm{~min}$, which is related to the effective pinning force of $\mathrm{NbN}$ particles. The $\mathrm{NbN}$ particles with $117 \mathrm{~nm}$ in mean diameter and $3.1 \times 10^{-4}$ in volume fraction are sufficient to inhibit the austenite grain size effectively. However, at $1070^{\circ} \mathrm{C}$ with $t_{A}>120 \mathrm{~min}$ or at $1200^{\circ} \mathrm{C}$, they grow quickly because of the weakened pinning effect of $\mathrm{NbN}$ caused by its coarsening and decreased volume fraction. The growing trend of $\mathrm{NbN}$ particles at $1070^{\circ} \mathrm{C}$ is almost the same as that of austenite grain and the $\mathrm{NbN}$ particles coarsened rapidly. The occurrence of abnormal grain growth (AGG) at $1010^{\circ} \mathrm{C}$ for $960 \mathrm{~min}$ or at $1070^{\circ} \mathrm{C}$ for $180 \mathrm{~min}$ can be attributed to the heterogeneity of $\mathrm{NbN}$ particles, e.g. non-uniform distribution, different size and interparticle distance. It is also demonstrated that the high energy grain boundaries whose misorientation range is $20-45^{\circ}$ may also be responsible for AGG.

\section{Acknowledgements}

This work is supported by the National Basic Research Program of China (973Program, Grant No. 2011CB012904 
and 2011CB706604), and by CNC machine tools and basic manufacturing equipment technology comments II (Grant No. 2011ZX04014-052 and 2012ZX04012011). The authors greatly acknowledge helpful discussions with Prof. Shipu Chen, School of Materials Science and Engineering, Shanghai Jiao Tong University.

\section{REFERENCES}

1) R. Hanus, F. Schuster, A. Buberl and H. Cerjak: 6 th Liege Conf. "Materials for Advanced Power Engineering", Forschungszentrum Juelich GmbH, Germany, (1998), 5.

2) M. Kimura, K. Yamaguchi, M. Hayakawa, K. Kobayashi and K. Kanazawa: Int. J. Fatigue, 28 (2006), 300.

3) C. Zener: Trans. AIME, 175 (1948), 15.

4) T. Gladman: Proc. R. Soc. London, Ser. A, 294 (1966), 298.

5) P. Hellman and M. Hillert: Scand. J. Metall., 4 (1975), 211.

6) M. Hillert: Acta Metall., 36 (1988), 3177.

7) P. Rios: Acta Metall., 35 (1987), 2805.

8) R. Elst, J. Van Humbeeck and L. Delaey: Acta Metall., 36 (1988), 1723.

9) S. Estay, L. Chengji and G. Purdy: Can. Metall. Q., 23 (1984), 121.

10) L. Cuddy and J. Raley: Metall. Trans. A, 14 (1983), 1989.

11) N. Zavaleta Gutiérrez, M. I. Luppo and C. A. Danón: ISIJ Int., 47 (2007), 1178.

12) M. Shome, D. Sarma, O. Gupta and O. Mohanty: ISIJ Int., 43 (2003), 1431

13) L. Fu, A. Shan and W. Wang: Acta Metall. Sin., 46 (2010), 832.

14) L. Han, R. Chen, J. Gu and J. Pan: Acta Metall. Sin., 45 (2009), 1446.

15) G. F. Vander Voort: Metallography, Principles and Practice, McGrawHill Books, New York, (1984), 440.

16) L. Barlow and M. Du Toit: J. Mater. Eng. Perform., 21 (2012), 1327.

17) K. Maile: Int. J. Pres. Ves. Pip., 84 (2007), 62.

18) K. Narita: Trans. Iron Steel Inst. Jpn., 15 (1975), 145.

19) R. Smith: Trans. Met. Soc. AIME, 224 (1962).

20) T. M. Hoogendoorn and M. Spanraft: Proc. Conf. on Microalloying 75, Union Carbide Corporation, New York, (1977), 75.

21) R. Sharma, V. Lakshmanan and J. Kirkaldy: Metall. Trans. A, 15 (1984), 545.

22) K. Balasubramanian and J. S. Kirkaldy: Proc. Int. Symp., ed. by J. D. Embury, Pergamon Press, Oxford, (1988), 37

23) H. D. Kim and I. S. Kim: ISIJ Int., 34 (1994), 198.

24) C. Elias and C. D. C. Viana: J. Mater. Eng. Perform., 1 (1992), 751.

25) I. Andersen, Ø. Grong and N. Ryum: Acta Metall. Mater., 43 (1995),
2689.

26) P. Villars and L. Calvert: Pearson's Handbook of Crystallographic Data for Intermetallic Compounds, American Society for Metals, 2nd, Materials Park, OH, USA, (1991), 44073.

27) N. Gao and T. Baker: ISIJ Int., 38 (1998), 744

28) P. Feltham: Acta Metall., 5 (1957), 97.

29) P. W. Voorhees: J. Stat. Phys., 38 (1985), 231.

30) S. G. Kim and Y. B. Park: Acta Mater., 56 (2008), 3739

31) A. Ray, S. K. Ray and S. Mediratta: J. Mater. Sci., 25 (1990), 5070.

32) K. Irvine, F. Pickering and T. Gladman: J. Iron Steel Inst., 205 (1967), 161.

33) J. Lake: Metall. Trans. A, 17 (1986), 1907

34) B. Garbarz and F. Pickering: Mater. Sci. Technol , 4 (1988), 967.

35) M. Ashby and K. Easterling: Acta Metall., 30 (1982), 1969.

36) J. Ion, K. E. Easterling and M. Ashby: Acta Metall., 32 (1984), 1949.

37) O. Akselsen, Ø. Grong, N. Ryum and N. Christensen: Acta Metall., 34 (1986), 1807.

38) R. Shimizu, J. Harase and D. Dingley: Acta Metall. Mater., 38 (1990), 973.

39) J. Harase, R. Shimizu and D. Dingley: Acta Metall. Mater., 39 (1991), 763

40) S. Fortunati, G. C. Abbruzzese and A. Campopiano: Mater. Sci. Forum, 94 (1992), 405.

41) P. Lin, G. Palumbo, J. Harase and K. Aust: Acta Mater., 44 (1996), 4677.

42) N. Rajmohan, J. Szpunar and Y. Hayakawa: Acta Mater., 47 (1999), 2999.

43) A. Rollett and W. Mullins: Scr. Mater., 36 (1997), 975.

44) G. Grest, M. Anderson, D. J. Srolovitz and A. Rollett: Scr. Metall. Mater., 24 (1990), 661.

45) D. Srolovitz, G. Grest and M. Anderson: Acta Metall., 33 (1985), 2233.

46) A. Rollett, D. J. Srolovitz and M. Anderson: Acta Metall., 37 (1989), 1227.

47) S. Ling: JOM, 44 (1992), 30

48) Y. Hayakawa, J. Szpunar, G. Palumbo and P. Lin: J. Magn. Magn. Mater., 160 (1996), 143

49) Y. Hayakawa and J. Szpunar: Acta Mater., 45 (1997), 1285.

50) Y. Hayakawa and J. Szpunar: Acta Mater., 45 (1997), 4713.

51) D. Titorov: Fiz. Met. Metalloved, 35 (1973), 1299.

52) D. Titorov: Phys. Met. Metallogr. (Russia), 77 (1994), 73.

53) G. Gottstein and F. Schwarzer: Mater. Sci. Forum, 94 (1992), 187.

54) M. J. Edirisinghe, B. Ralph, Z. Huda, K. B. Shim and J. Furley: Mater. Sci. Forum, 94 (1992), 129.

55) S. Babcock and R. Balluffi: Acta Metall., 37 (1989), 2367.

56) W. Hahn and H. Gleiter: Acta Metall., 29 (1981), 601

57) T. Watanabe: Mater. Sci. Forum, 94 (1992), 209. 